\title{
Thermal Modeling of an Advanced Geared Turbofan for Distributed Engine Control Application
}

Jonathan Kratz (NASA GRC)

Dennis Culley (NASA GRC)

George Thomas (N\&R Engineering)

AIAA Propulsion \& Energy Forum

10 July 2018 


\section{Outline}

Summary

- Presents a method for modeling the dynamic thermal environment of a gas turbine engine with an eye toward control system component reliability as it relates to the implementation of distributed engine control.

- Application is to a conceptual N+3 generation geared turbofan.

- The resulting model is shown to run in real-time within a multi-model simulation environment that demonstrates the ability to interact with hardware to drive test equipment

Outline

- Background/Motivation

- Thermal Modeling Methodology

- Thermal Modeling Techniques

- Application to an Advanced Geared Turbofan

- Real-Time Capabilities

- Summary 


\section{Background: Distributed Engine Control}

Current Control Approach

- Centralized architecture performed through a full authority digital engine controller (FADEC)

- Constrains the control system topology and limits capability

Distributed Engine Control

- Hardware-driven strategy that adds flexibility

- Modularizes the control system and distributes control functions to smart nodes located across the engine

- Utilizes a light-weight digital communication network

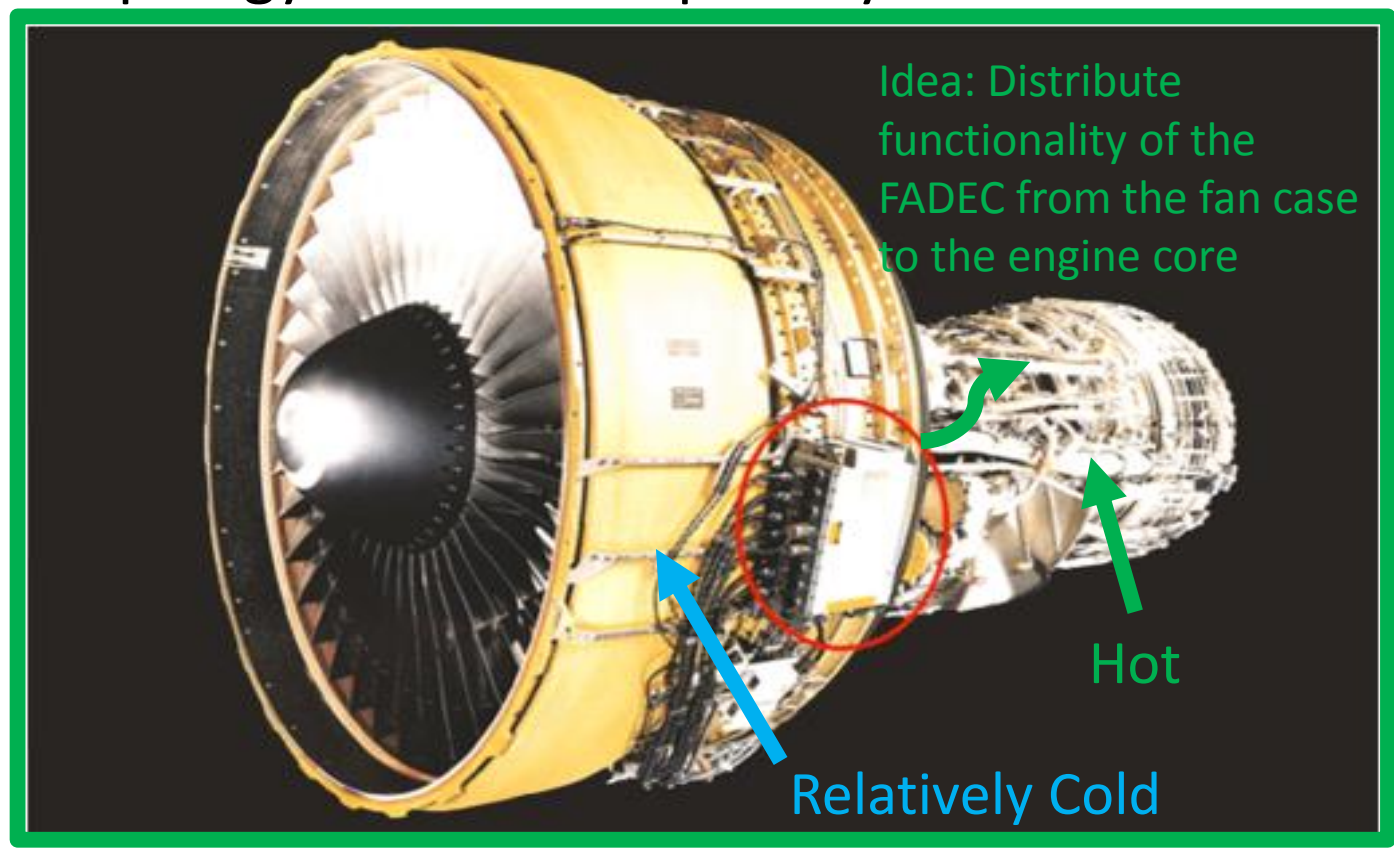

- Some Potential Benefits: Reduce weight, reduce volume impact, alleviate obsolescence and certification issues, enable more advanced control 


\section{Background: High Temperature Electronics}

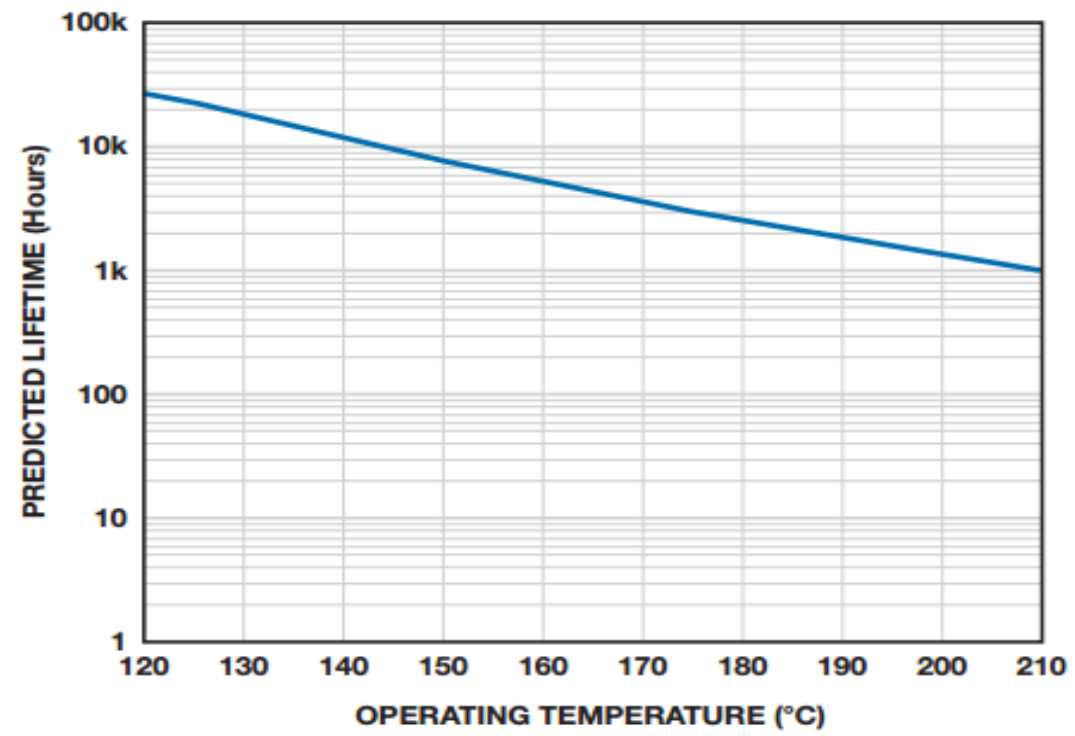

Example of the reliability vs. temperature relationship for an electronic device http://www.analog.com/library/analogdialogue/archives/4604/high_temp_electronics.pdf
- Desire to mount smart nodes on the engine core

- Challenging thermal environment

- State-of-art material for internal gas path exceed $1500^{\circ} \mathrm{C}$

- Common consumer electronics operate reliably $<70^{\circ} \mathrm{C}$, sometimes $150^{\circ} \mathrm{C}$

- Inverse relationship between temperature and electronic reliability

- High-Temp electronics

- Silicon-On-Insulator (SOI): Up to $300^{\circ} \mathrm{C}$ $\left(225^{\circ} \mathrm{C}\right.$ near term)

- Silicon Carbide: $500^{\circ} \mathrm{C}+$

- Important considerations: Max \& min temperature (steady-state), rate of change in temperature (dynamic), \& temperature cycling (dynamic)

- Objective: Develop a thermal model of the relevant engine structure to estimate the environment in which DEC electronics will be placed + develop re-useable modeling tools + develop capability to use the model and or its results to drive test equipment

\section{"High temperature is relative"}




\section{Thermal Modeling Methodology}

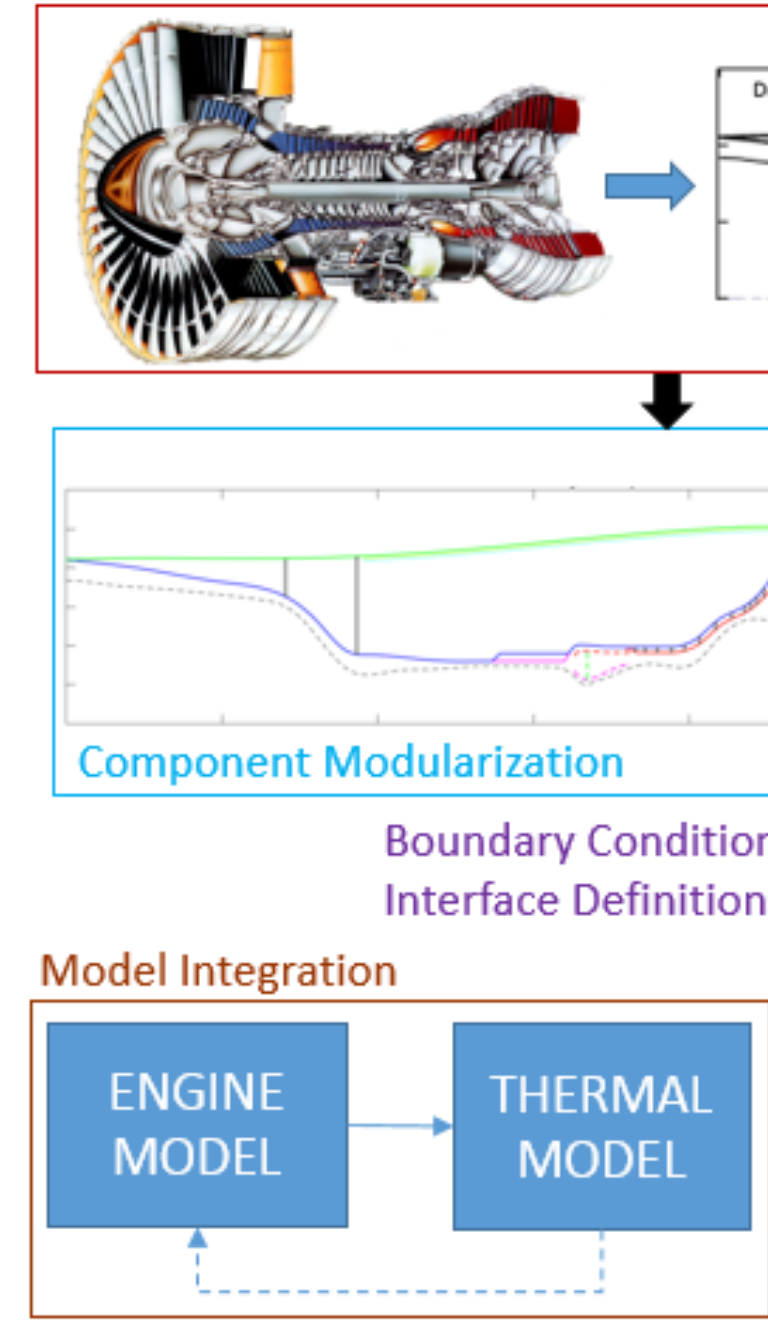

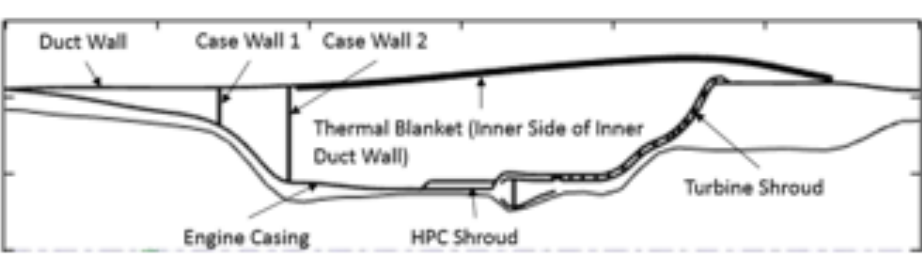

Simplified Geometric Representation
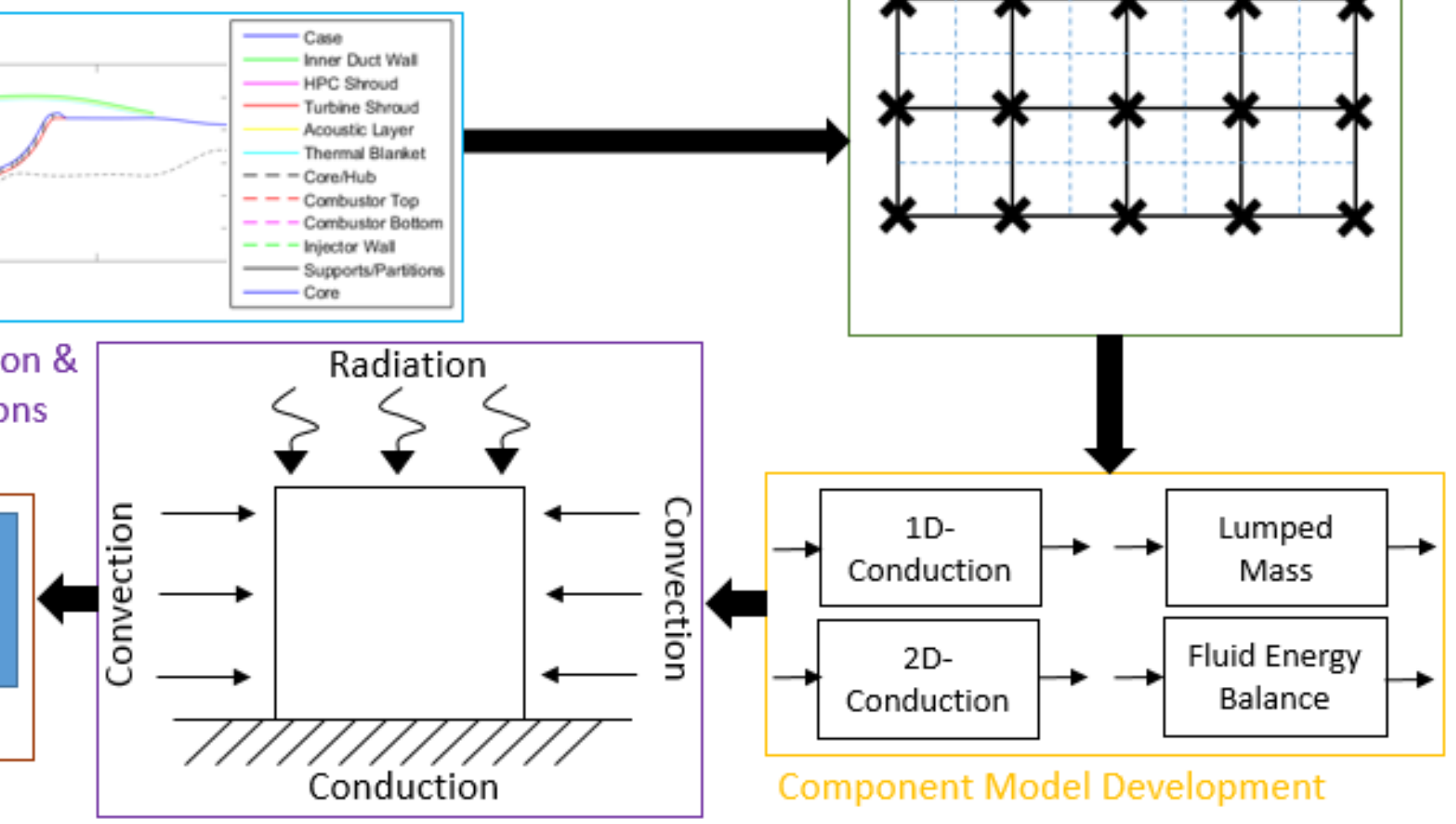

Component Model Development

Discretization

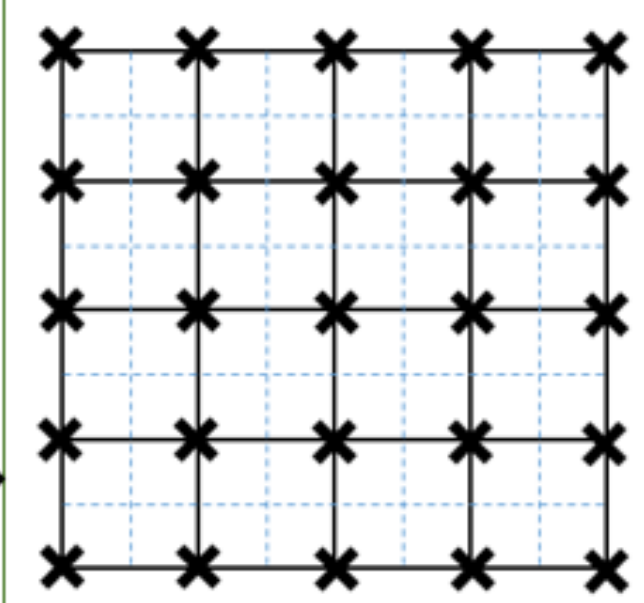

5 


\section{Thermal Modeling Techniques}

\section{Structure}

- 2-D Finite Difference Method (FDM) - More significant components (engine casing, shrouds, duct wall, etc.)

$$
\begin{gathered}
\frac{\partial T}{\partial t}=\frac{1}{\rho C_{p}} \nabla \cdot(k \nabla T) \rightarrow \frac{\partial T}{\partial t}=\frac{1}{\rho C_{p}}\left[\left(\frac{\partial k}{\partial r}+\frac{k}{r}\right) \frac{\partial T}{\partial r}+k \frac{\partial^{2} T}{\partial r^{2}}+\frac{\partial k}{\partial z} \frac{\partial T}{\partial z}+k \frac{\partial^{2} T}{\partial z^{2}}\right] \\
T=\text { temperature, } t=\text { time, } \rho=\text { density, } C_{p}=\text { heat capacity, } k=\text { thermal conductivity, } \\
r=\text { radial direction coordinate, } z=\text { axial direction coordinate }
\end{gathered}
$$

- Model the component as a cylindrical shell of constant radius and thickness

- Discretized and then solved using a 2-D implicit scheme

- Lumped Capacitance - Less significant components (core components - compressor and turbine blades)

$$
\frac{\partial T}{\partial t}=\frac{1}{m C_{p}} \underbrace{\left[h A\left(T_{F}-T\right)\right.}+\underbrace{\left.u A\left(T_{R}-T\right)\right]}
$$

\section{Convection Radiation}

$m=$ effective mass, $A$ = surface area, $T_{F}=$ temperature of convecting fluid, $T_{R}=$ temperature of radiating body,

$h=$ convection heat transfer coefficient, $u=$ radiation heat transfer coefficient 


\section{Thermal Modeling Techniques}

Flow Paths \& Voids

- Engine simulation data used for gas paths and some bleed flows

- Fluid Energy Balance - used for bleed flows of significant heat transfer and relatively low mass flow

$$
\begin{aligned}
& Q=\sum_{\text {out }}\left(\dot{m} C_{p} T\right)-\sum_{\text {in }}\left(\dot{m} C_{p} T\right) \\
& T=\text { temperature, } C_{p}=\text { heat capacity, } \\
& \dot{m}=\text { mass flow rate, } Q=\text { heat }
\end{aligned}
$$

- Average of Surroundings used for closed volumes with no forced air flow
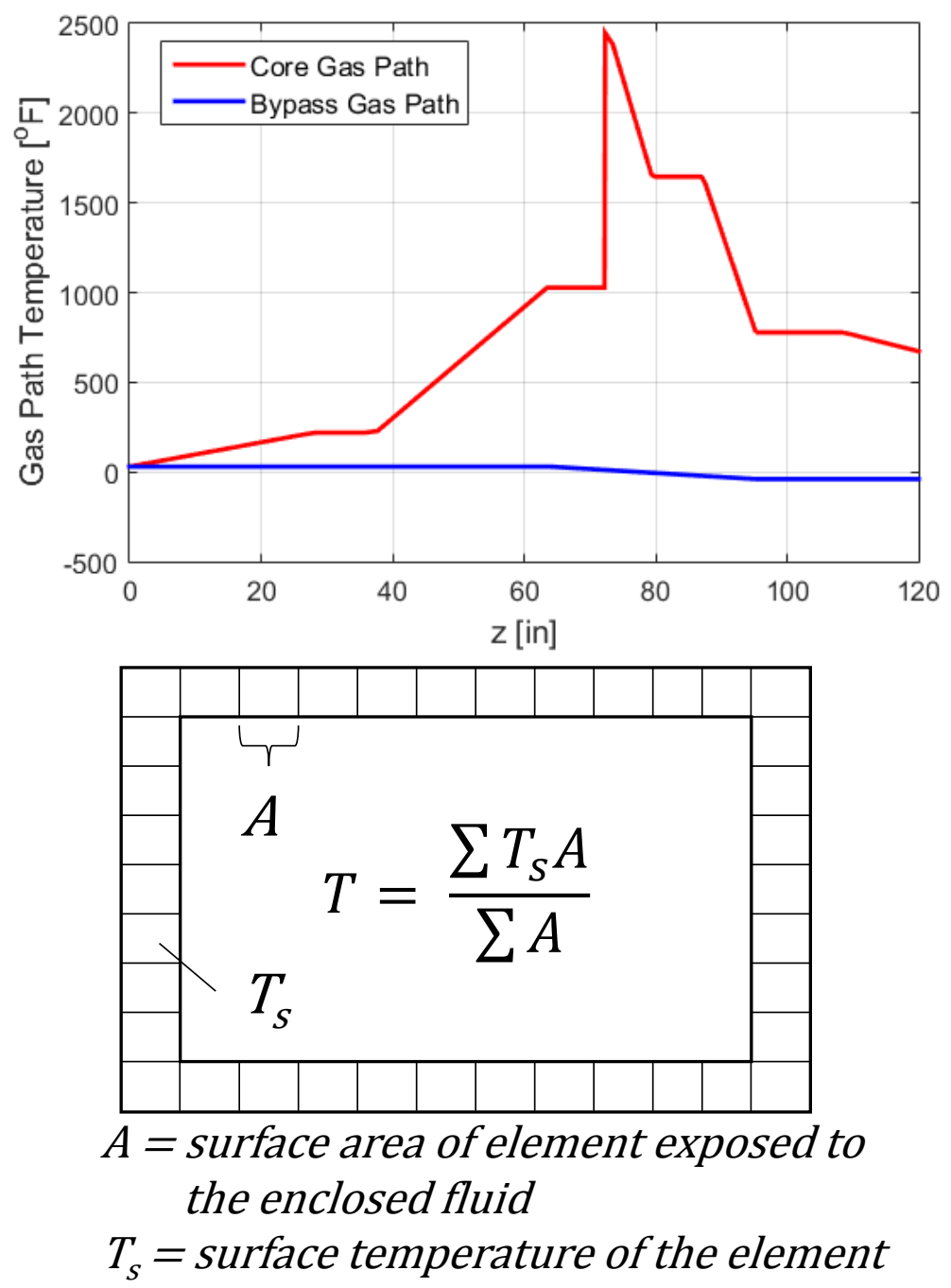


\section{Thermal Modeling Techniques}

\section{Boundary Conditions}

- Conduction

- Thermal capacitance of each boundary node is computed to enable conduction boundary conditions to be applied at the interface of 2 solid components

- Convection

- Forced and natural convection are considered

- Relations used for the coefficient $h$ are generic and tunable

- Tuning variables were set based on guidance from studies conducted at NASA and information found in literature

- Radiation

- Written in a linear form

- The coefficient $u$ is a strong function of temperature and is updated each timestep of the simulation.

- Relations for $u$ assumes radiation between reflective concentric cylinders

- Assumed radiation only occurs between parallel surfaces

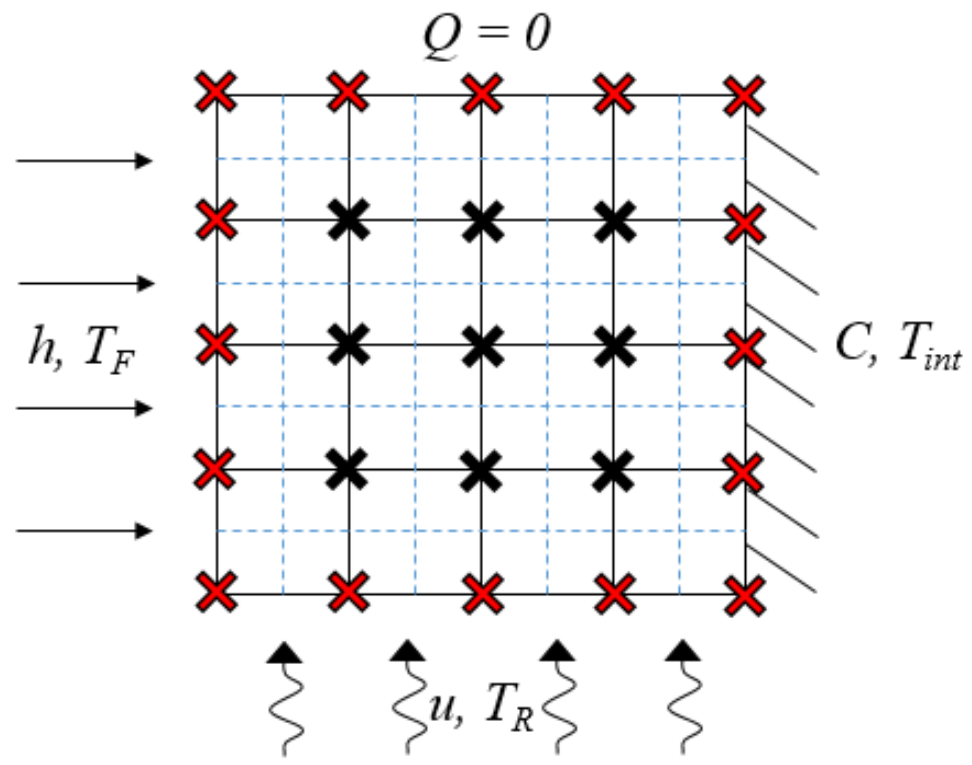

$Q=$ heat

$h=$ convection heat transfer coefficient

$T_{F}=$ fluid temperature

$u=$ radiation heat transfer coefficient

$T_{R}=$ temperature of radiating body

$C=$ thermal capacitance

$T_{\text {int }}=$ temperature at the interface between 2 solids 


\section{Thermal Modeling Techniques}

\section{Thermal System Analysis Toolbox (TSAT)}

- Library of tools developed in the MATLAB/Simulink environment

- Topics modeled

- Conduction

- Convection

- Radiation

- Deformation

- Air Properties

- Fluid Heat Transfer

- General Tools

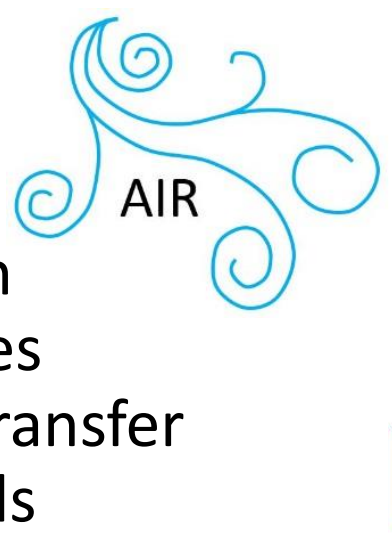

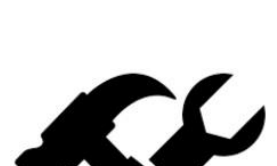

- Provides building blocks for building up and modeling dynamic thermal systems
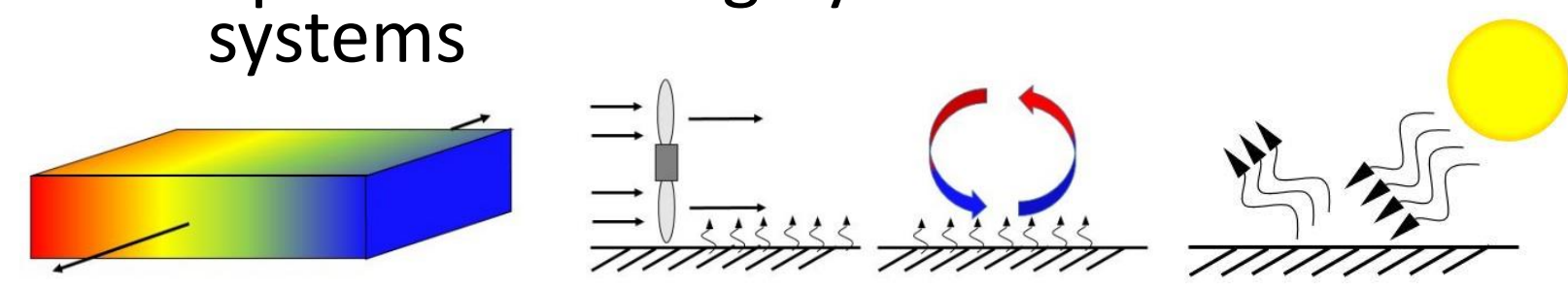

Download Link: https://github.com/nasa/TSAT

Thermal Conductivity Matrix $\{k\}$

Heat Capacity Matrix [Cp]

Density Matrix [rho]

X Left Surface Convection BC [TfL, hL]

YLeft Surface Radiation BC [TextL, uL]

YLeft Surface Conduction BC [TSL, CL]

X Right Surface Convection BC [TfR, hR]

Xight Surface Radiation BC [TextR, uR]

Right Surface Conduction BC [TsR, CR]

Xottom Surface Convection BC [TfB, hB]

X Bottom Surface Radiation BC [TextB, UB]

Bottom Surface Conduction BC [TSB, CB] Thermal Conductance $\{\mathrm{C}\}$,

Top Surface Convection BC [TfT, hT]

Top Surface Radiation BC [TextT, UT]

Top Surface Conduction BC [TST, CT]

2D Transient Conduction Model - Fully Implicit

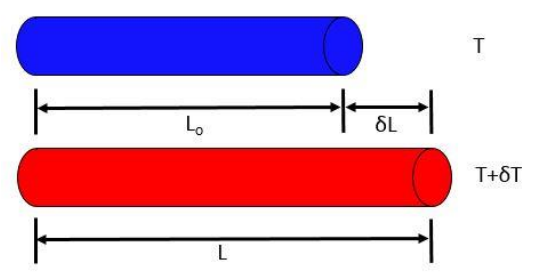




\section{Application: The Engine}

Advanced Geared Turbofan 30,000lb (AGTF30)

- Based on the NASA N+3 NPSS reference engine

- $3^{\text {rd }}$ generation geared turbofan

- Features a compact gas turbine (CGT) and a variable area fan nozzle

- Capable of producing 30,000 $\mathrm{lb}_{\mathrm{f}}$ of thrust at the sea-level static condition

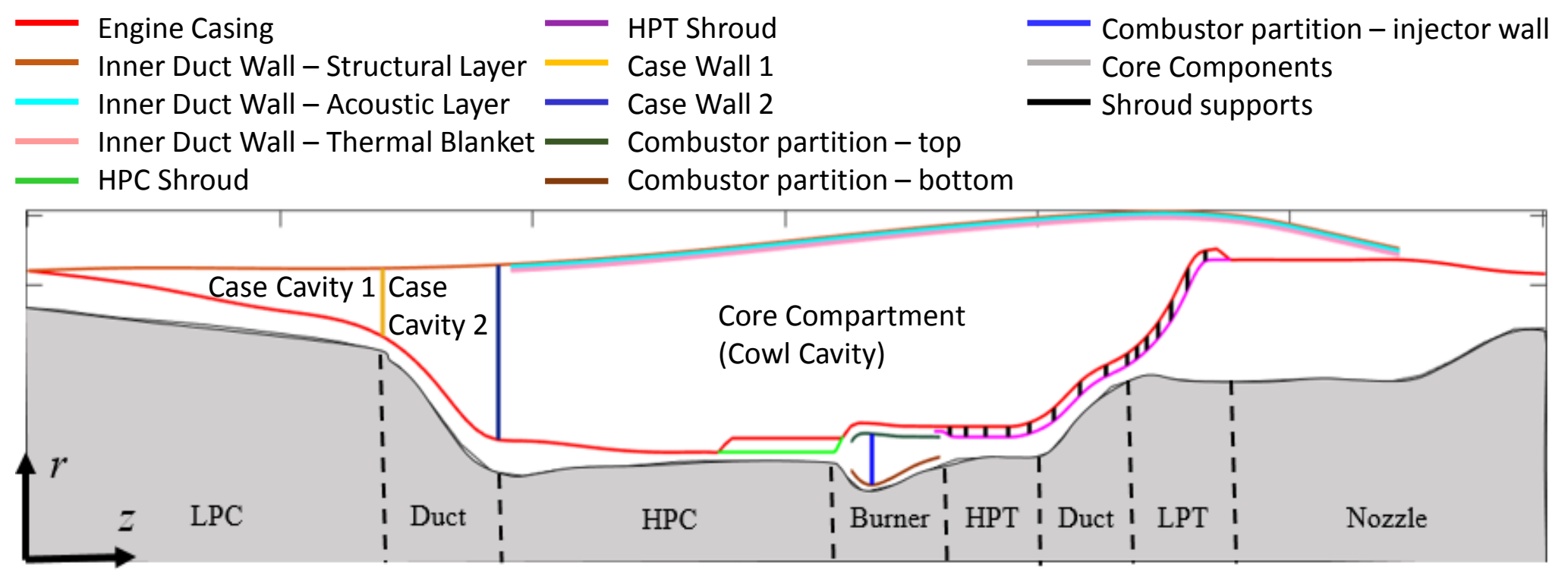




\section{Application: The Engine Air Flow}
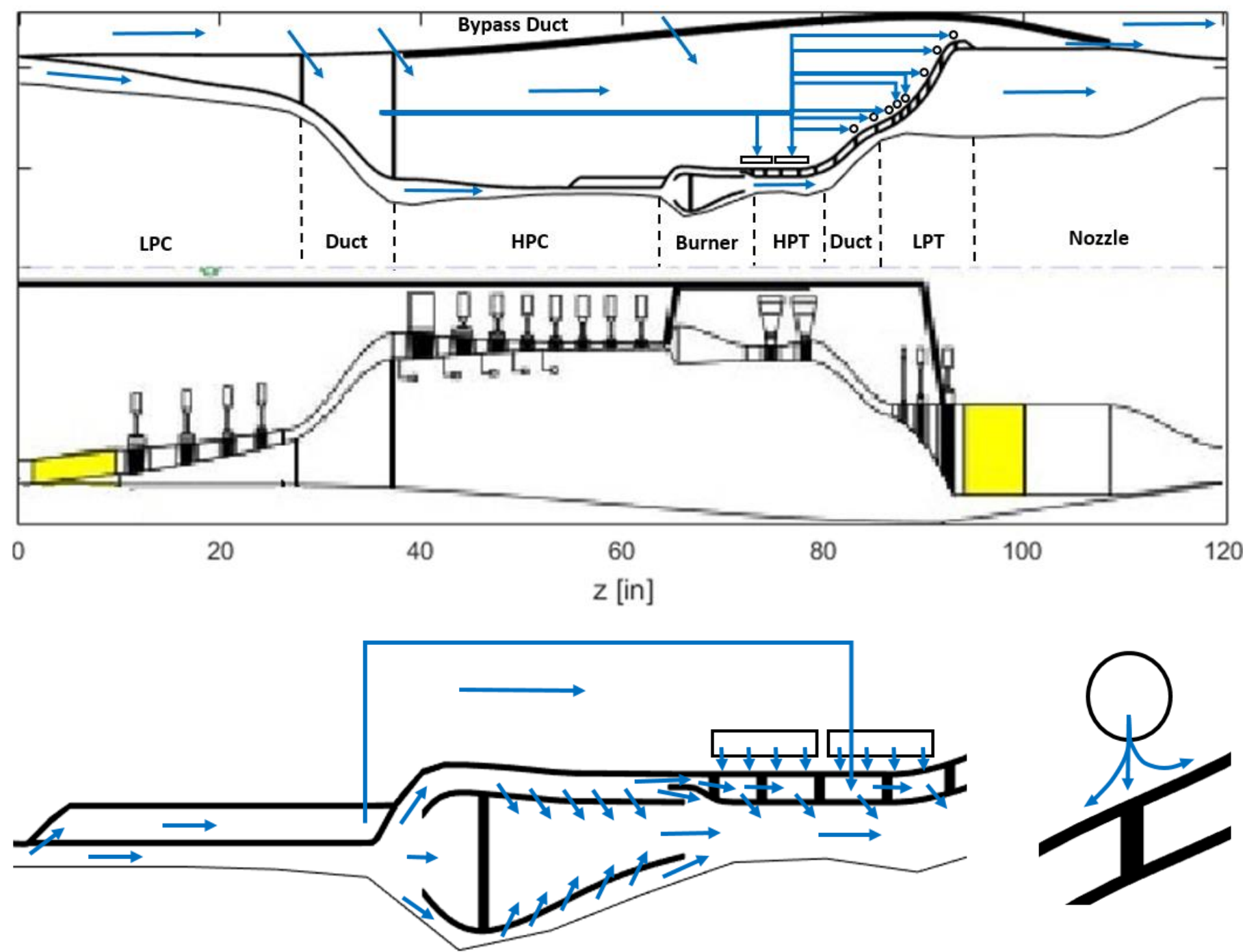


\section{Application: Modeling}

- Structures

- All components except the "core components" were modeled with 2-D FDM

- Geometry was approximated as a cylindrical shell of the components average radius and thickness

- Various levels of discretization were investigated

- Core components utilized a lumped capacitance model

- Important cavities and voids

- Bypass flow path, core flow path, and case cavity 2 temperatures were driven by the engine model simulation

- Case cavity 1 temperature was approximated as the average of its surrounding structure

- Core compartment temperature was approximated using the fluid energy balance method

- Boundary conditions and interfaces between models were defined

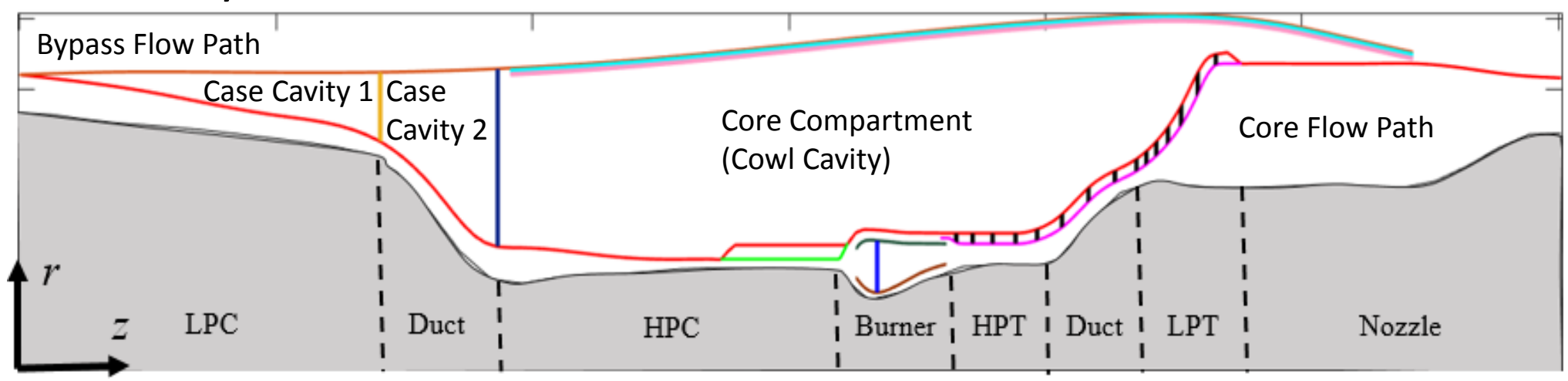




\section{Application: Flight Profile}

- Flight profile constructed from real data

- The starting and ending destinations are unknown but is representative of a $\sim 250 \mathrm{mi}$ flight

- Cleveland, Ohio to Washington D.C. or Las Vegas, Nevada to Los Angeles, California

- At the start of the simulation all structures are initialized at ambient temperature

- After the flight, the thermal simulation is extended to investigate heat soak back (modeling details are not provided here for the sake of time - see the paper)
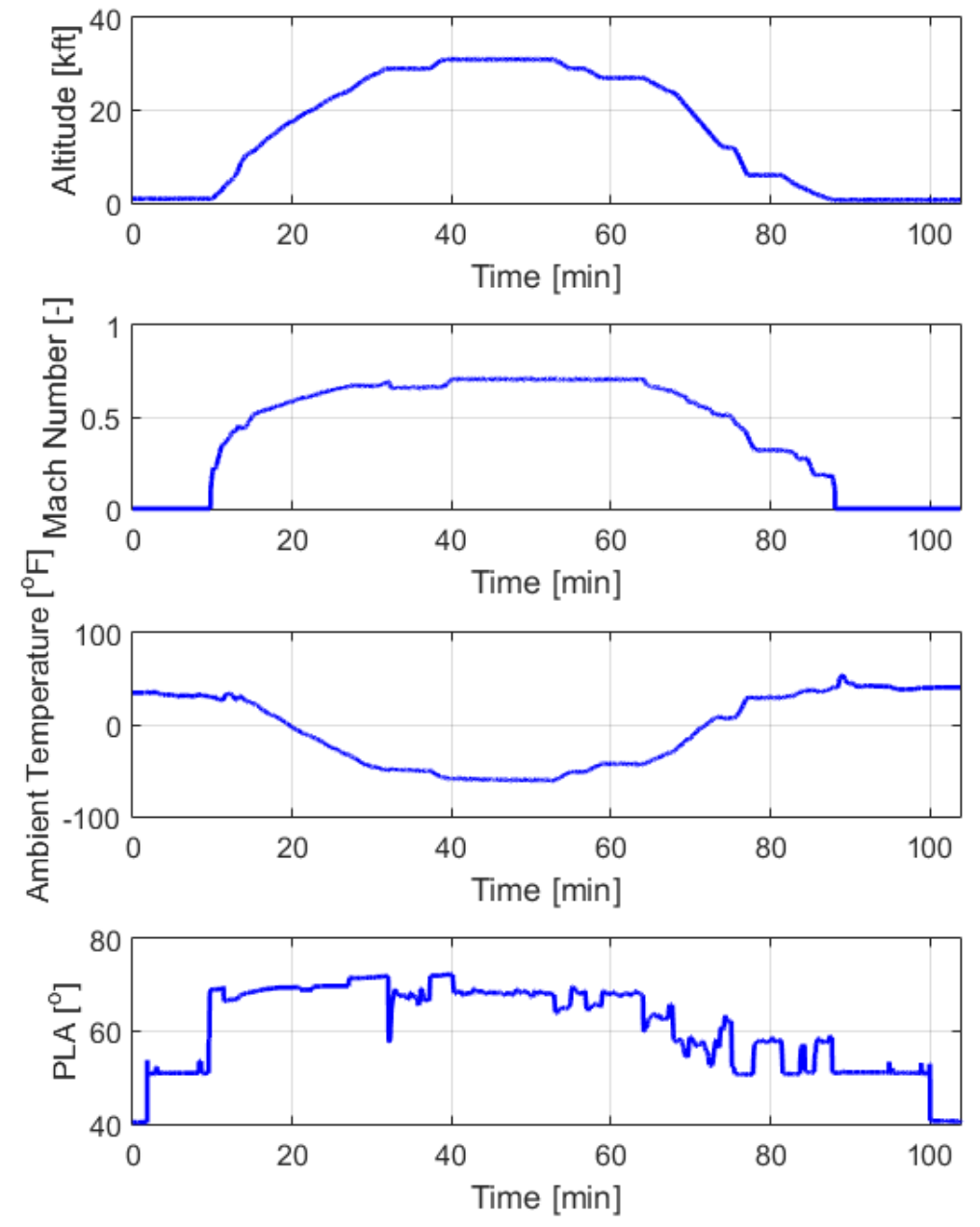

PLA = power lever angle 


\section{Application: Results}
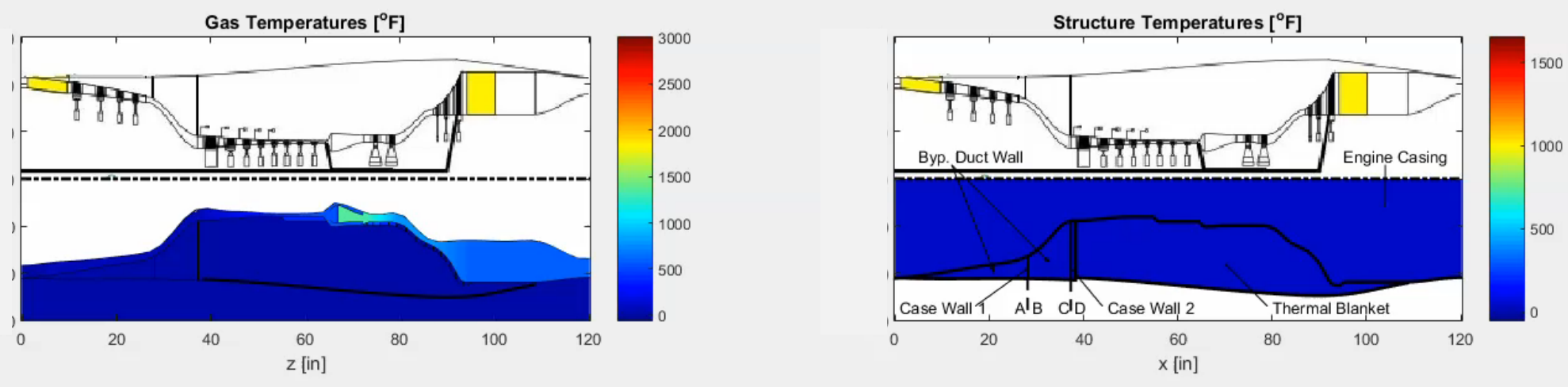

Time: 0 min
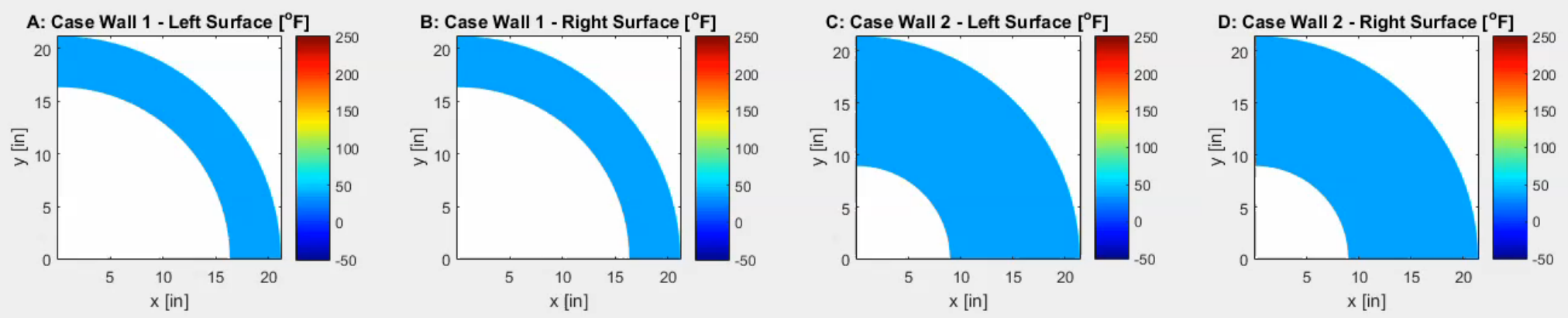


\section{Application: Results}

- Compartments

- Case Cavity 1: Up to $125^{\circ} \mathrm{F}$

- Case Cavity 2: Up to $155^{\circ} \mathrm{F}$

- Core Compartment (Cowl Cavity): Up to 650 ${ }^{\circ} \mathrm{F}\left(400^{\circ} \mathrm{F}\right.$ upstream of the inter-turbine duct)

- Structure

- Engine Casing: Up to $1580{ }^{\circ} \mathrm{F}\left(1100{ }^{\circ} \mathrm{F}\right.$ outside the inter-turbine duct)

- Inner Duct Wall (Thermal Blanket): Up to 600 ${ }^{\circ} \mathrm{F}\left(350{ }^{\circ} \mathrm{F}\right.$ upstream of the inter-turbine duct)

- Case Wall 1: Up to $220^{\circ} \mathrm{F}$

- Case Wall 2: Up to $220^{\circ} \mathrm{F}$

- Observations

- Rate of change in temperature

- Compartments: $-2.5^{\circ} \mathrm{F} / \mathrm{sec}-2.5^{\circ} \mathrm{F} / \mathrm{sec}$

- Structures: $-2.5{ }^{\circ} \mathrm{F} / \mathrm{sec}-5^{\circ} \mathrm{F} / \mathrm{sec}$

- Maximum temperatures occurred at different parts of the engine during different times including: the cold startup of the engine, during climb, during cruise, and during heat soak back
Engine Casing - Maximum Temperature $\left[{ }^{\circ} \mathrm{F}\right]$
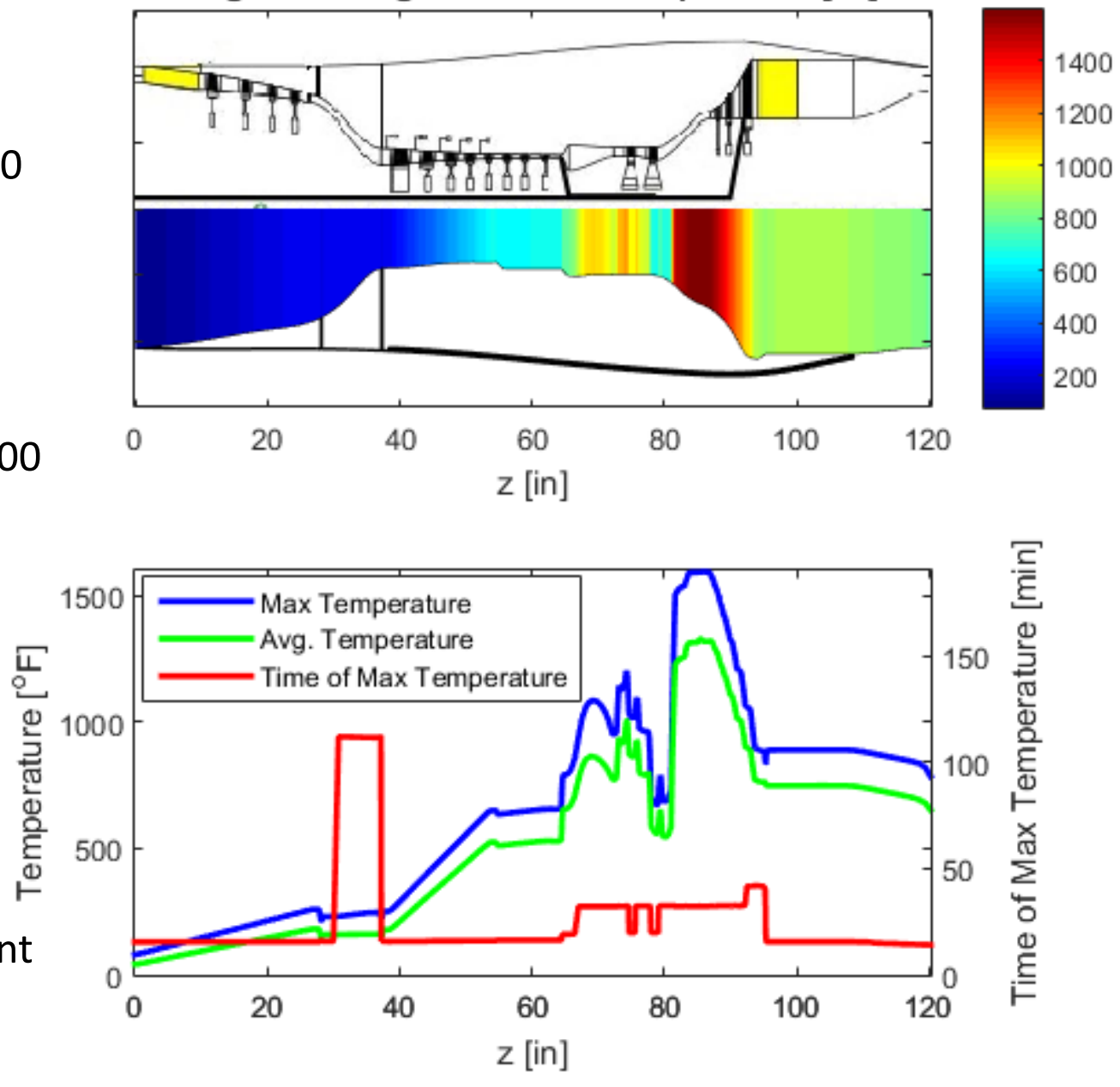


\section{Application: Results}

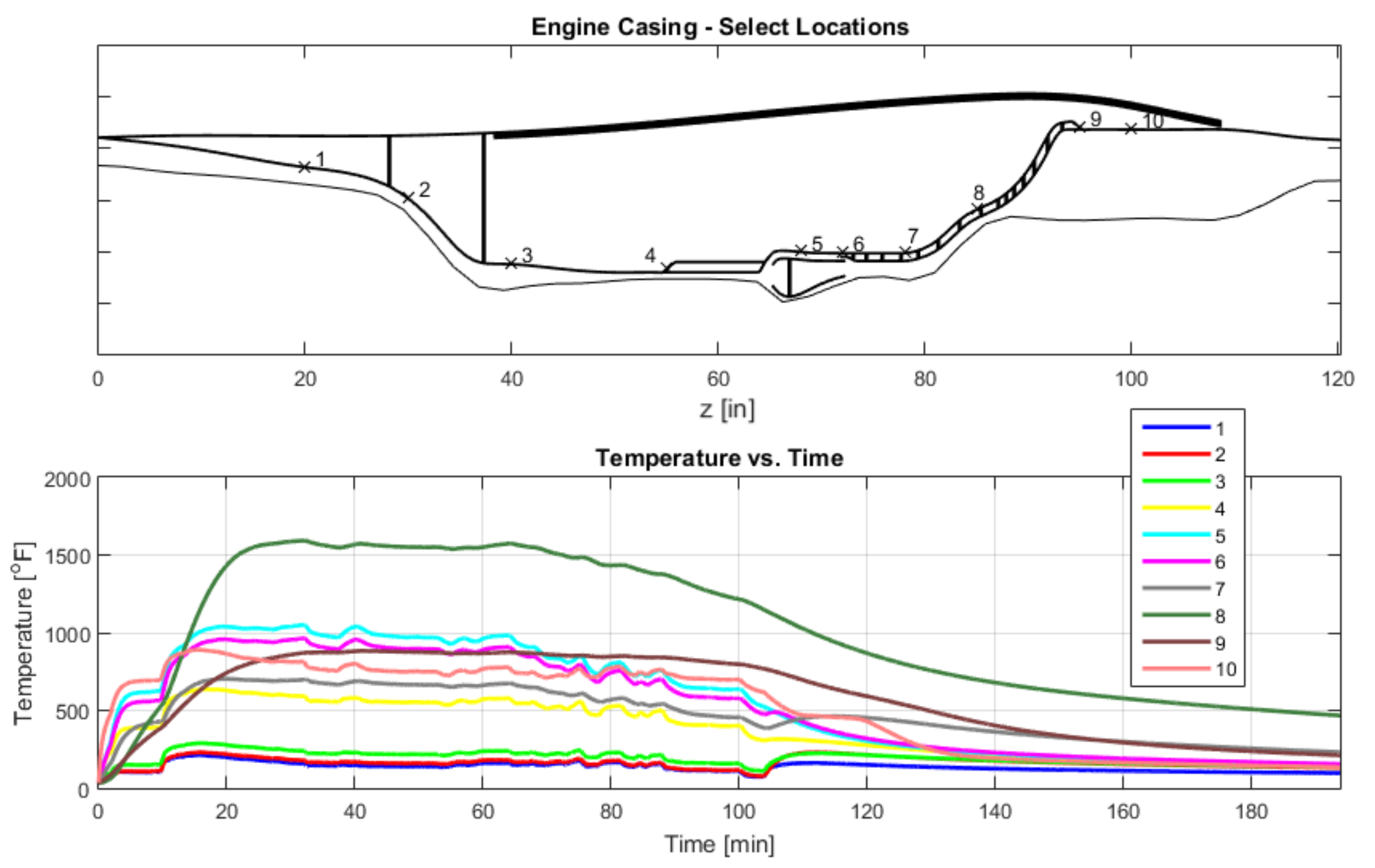




\section{Real-Time Capabilities}

- Model runs faster than real-time

- Migrated to the hardware-in-the-loop (HIL) system known as the Decentralized Engine Control System Simulator (DECSS)

- Integrated in a multi-model simulation including a physical network and simulated smart nodes

- Used the model to drive a real-time, full-size LED display

- Illustrates the ability to interact with test equipment

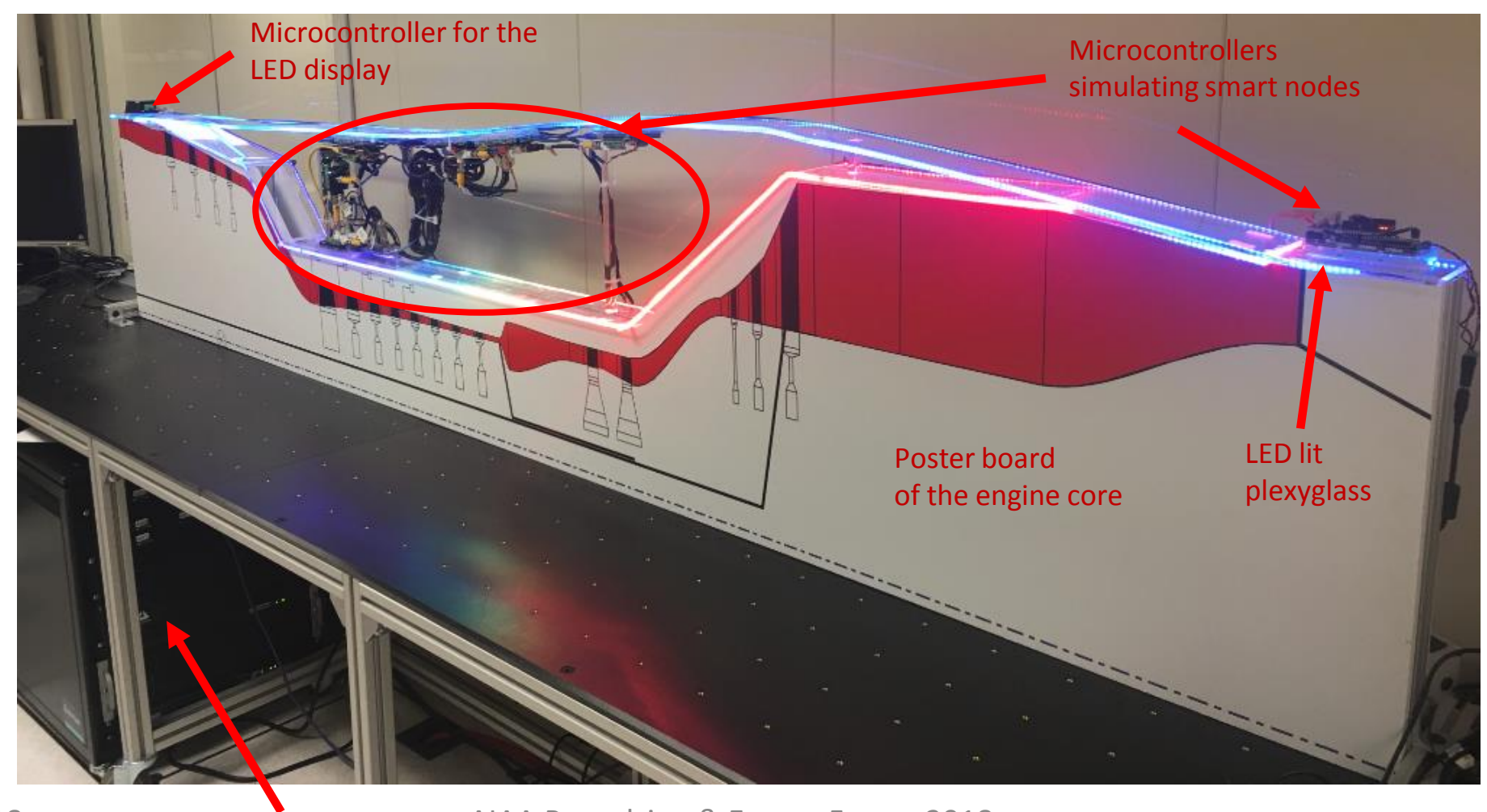




\section{Summary}

- Motivation for high level thermal modeling pertaining to distributed engine control has been discussed

- A thermal modeling methodology for gas turbine engines has been proposed

- An application of modeling methodology has been illustrated

- Results from the application have been presented and discussed

- Real-time capabilities have been demonstrated with eye toward hardware testing 


\section{Acknowledgements}

- Funded by the Transformational Tools and Technology (TTT) project under the Aerospace Research Mission Directorate (ARMD)

- NASA civil servants \& contractors who contributed in some way to this effort: Sanjay Garg, Scott Jones, Jonathan Litt, Jeffryes Chapman, Vikram Shyam, Paht Juangphanich, Ram Bhatt, Jerry Lang, James DiCarlo, Joe Grady, Dan Paxson, and Shane Sowers

- The Distributed Engine Control Working Group (DECWG ${ }^{\circledR}$ ) for providing input and guidance related to this work 


\section{Questions?}

Contact Information:

- Jonathan Kratz - jonathan.kratz@nasa.gov

- Dennis Culley - dennis.e.culley@nasa.gov

- George Thomas - george.I.thomas@nasa.gov

TSAT Link:

https://github.com/nasa/TSAT 


\section{EXTRA SLIDES}




\section{Background: Distributed Engine Control}

SN - Smart Node w/ Embedded Electronics

D-FADEC - FADEC in a DEC system

\section{Bypass Flow}

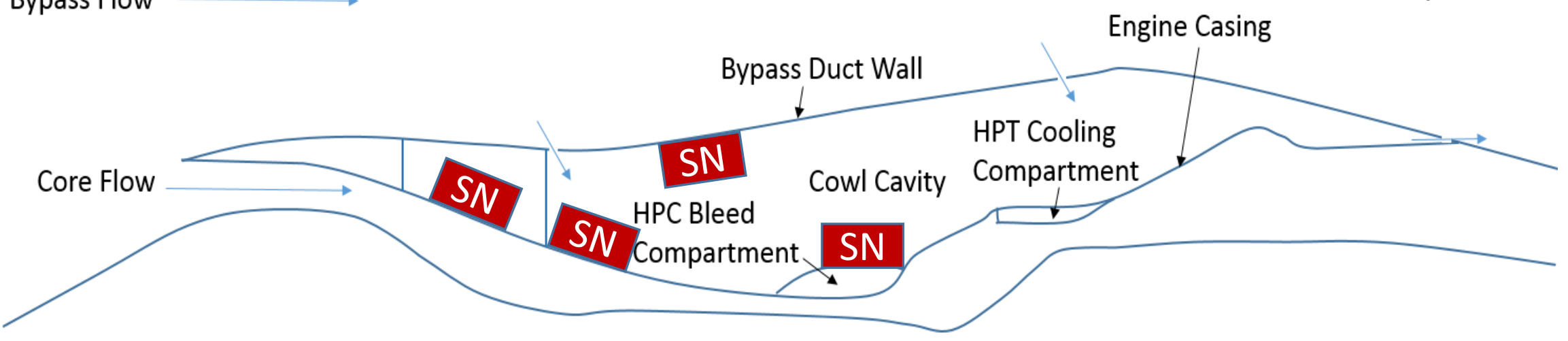

Engine Hub

\section{Engine Centerline}

Where can we mount hardware?

- SN mounting surfaces could include those exposed to the cowl cavity or case compartments (engine casing, bypass duct wall, $\&$ various supports structures) 


\section{Thermal Modeling Methodology}

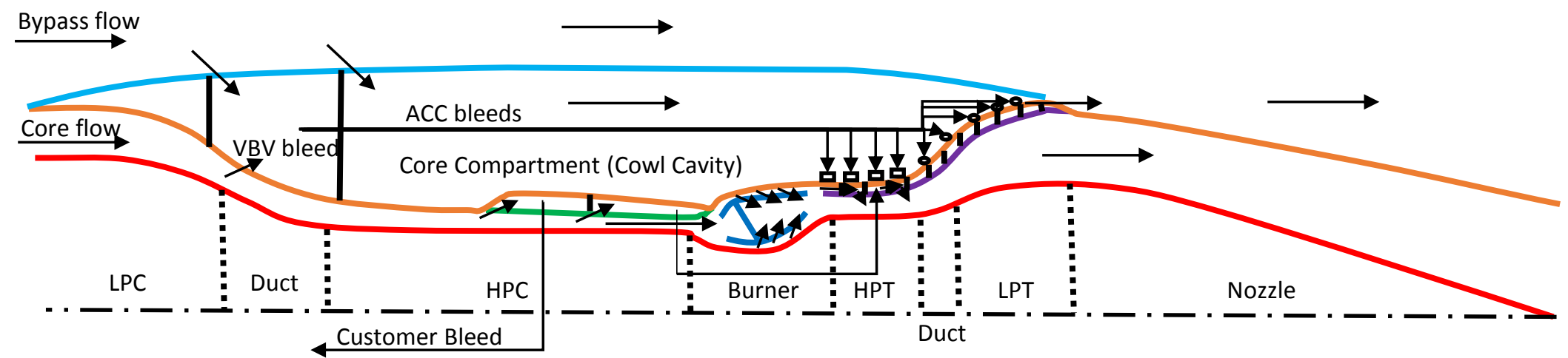

Structure Key Engine Casing Inner Duct Wall HPC Shroud Turbine Shroud Combustor

What part(s) of the engine are we interested in modeling?

- Any potential mounting structure for a smart node

- Any compartment in which a smart node could be mounted

- Any structure or flow path that could have significant implications on the thermal environment of a potential mounting locations Needs?

- Geometry/dimensions, secondary air system, other heat transfer/cooling mechanisms inherent in the design 


\section{Application: Results}

- Max T: $125^{\circ} \mathrm{F}$ during take-off (case cavity 1 ), $155^{\circ} \mathrm{F}$ during heat soak (case cavity 2 ), $400^{\circ} \mathrm{F}$ during climb (applicable portion of the cowl cavity)

- Max Increasing dT/dt: $1^{\circ} \mathrm{F} / \mathrm{sec}$ (case cavity 1 \& 2), 2.5 ${ }^{\circ} \mathrm{F} / \mathrm{sec}$ (applicable portion of the cowl cavity)

- Max Decreasing dT/dt: $0.5^{\circ} \mathrm{F} / \mathrm{sec}$ (case cavity 1 ), $2{ }^{\circ} \mathrm{F} / \mathrm{sec}$ (case cavity 2 ), $2.5^{\circ} \mathrm{F} / \mathrm{sec}$ (applicable portion of the cowl cavity)

- Observations

- Temperature rises several hundred degrees through the cowl cavity (core compartment)

- Case cavity 1 shows dampening effects comparted to the temperature response of case cavity 2
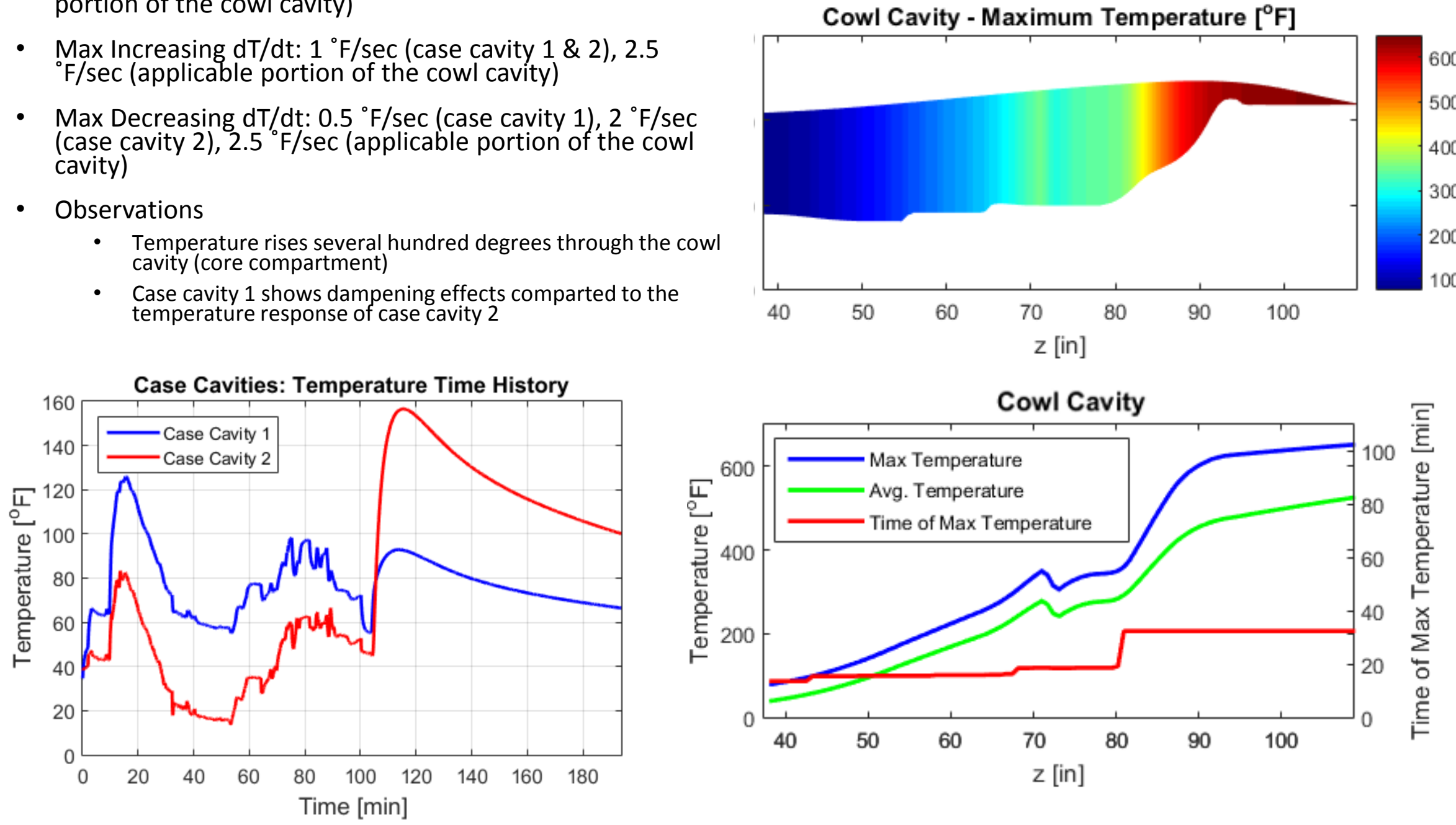


\section{Application: Results}

- Max T: $1580{ }^{\circ} \mathrm{F}\left(\sim 1100^{\circ} \mathrm{F}\right.$ neglecting inter-turbine duct)

- Max Increasing dT/dt: 5 ${ }^{\circ} \mathrm{F} / \mathrm{sec}$ (neglecting nozzle)

- Max Decreasing dT/dt: 2.5 ${ }^{\circ} \mathrm{F} / \mathrm{sec}$ (neglecting nozzle)

- Observations:

Engine Casing - Maximum Temperature $\left[{ }^{\circ} \mathrm{F}\right]$

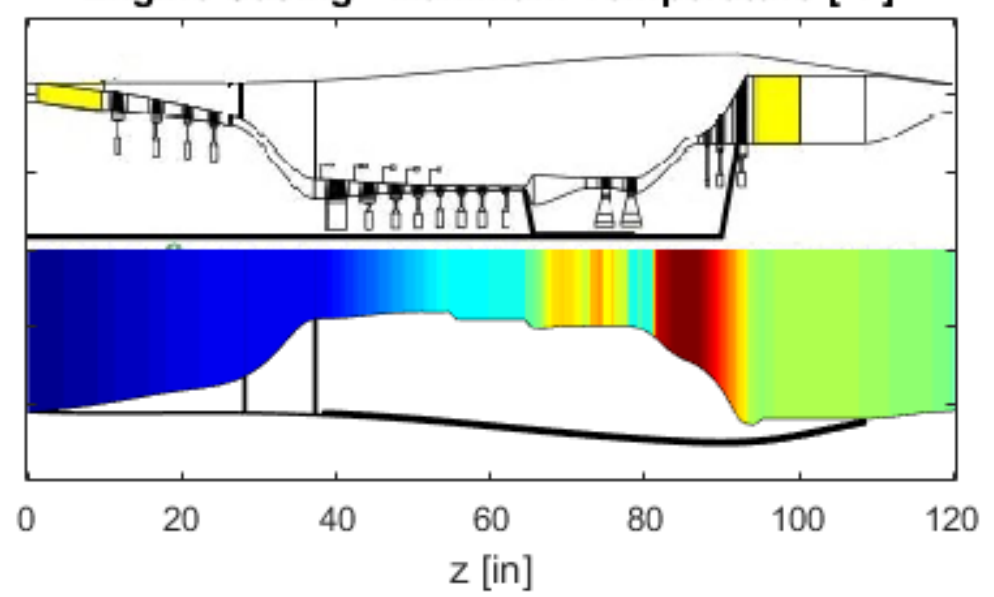

- Max temperature occurs in the inter-turbine duct region due high temperatures from the aggressive cycle design and lack of active cooling

- Max temperatures for

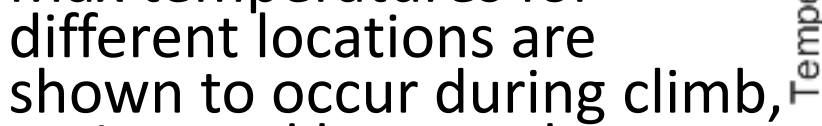
cruise, and heat soak

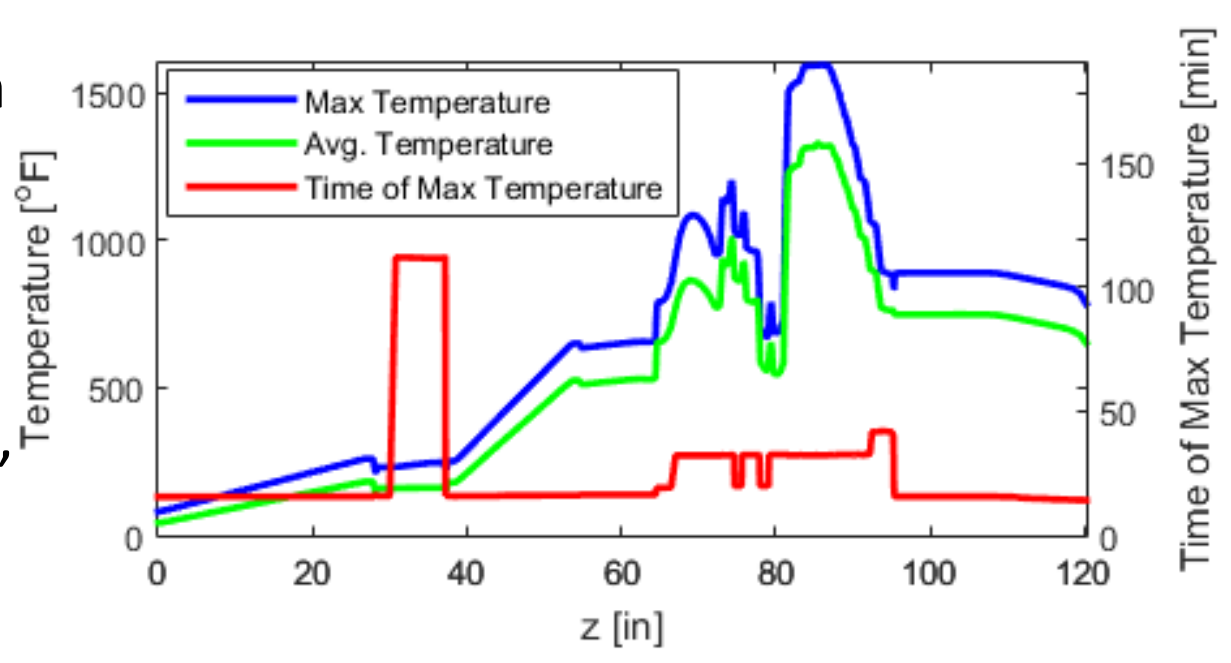




\section{Application: Results}

- Max T: $220^{\circ} \mathrm{F}$

- Max Increasing dT/dt: $\sim 1.3^{\circ} \mathrm{F} / \mathrm{sec}$ (at engine case), $\sim 0.3^{\circ} \mathrm{F} / \mathrm{sec}$ (away from the engine case)

- Max Decreasing dT/dt: $\sim 0.7^{\circ} \mathrm{F} / \mathrm{sec}$ (at engine case), $0.1^{\circ} \mathrm{F} / \mathrm{sec}$ (away from the engine case)

- Observations:

- Max temperature occur during heat soak, and to a lesser extent take-off
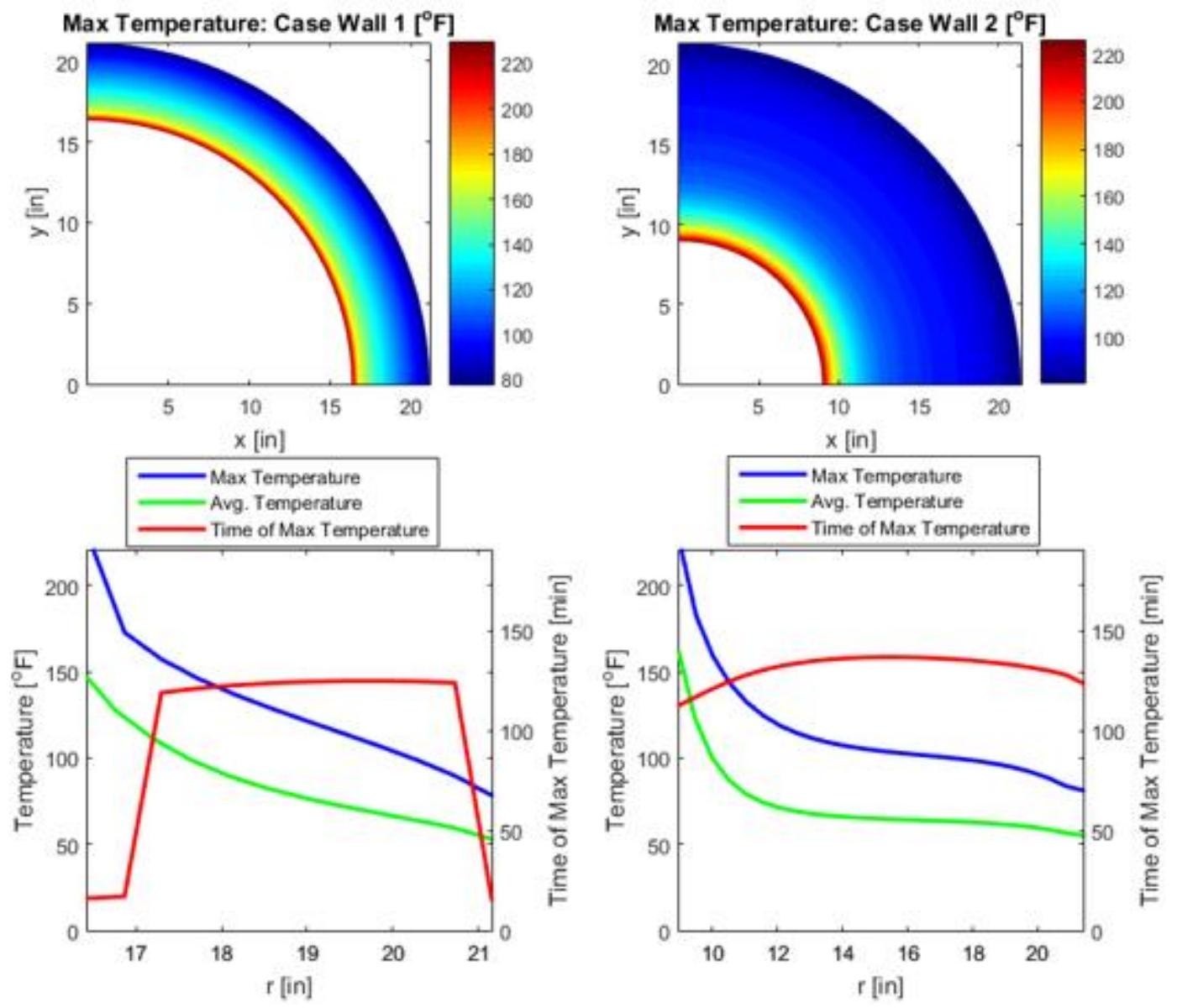


\section{Application: Results}

- Max T: $600{ }^{\circ} \mathrm{F}\left(\sim 350^{\circ} \mathrm{F}\right.$ for the region upstream of the inter-turbine duct)

- Max Increasing dT/dt: $2{ }^{\circ} \mathrm{F} / \mathrm{sec}$

- Max Decreasing dT/dt: $\sim 1.5^{\circ} \mathrm{F} / \mathrm{sec}$

- Observations:

- Max temperatures reached during climb to shortly after reaching cruise

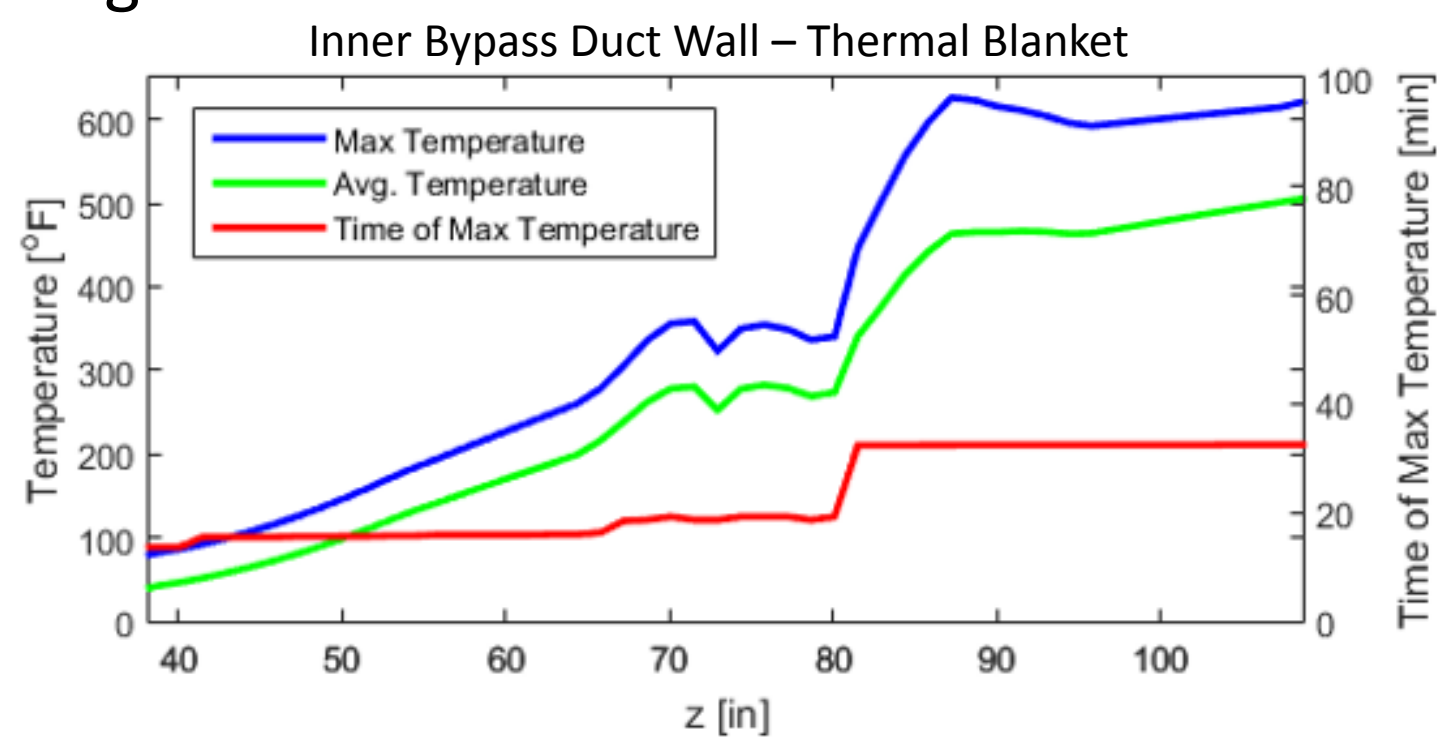




\section{Application: Results}

Thermal Blanket - Select Locations

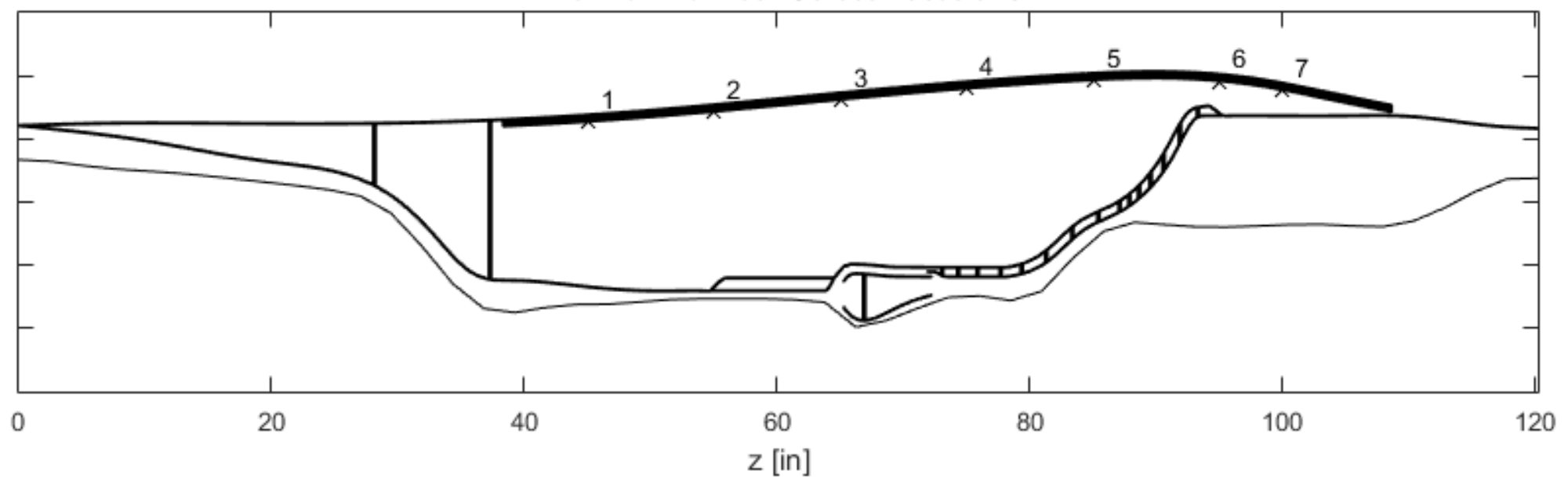

Temperature vs. Time

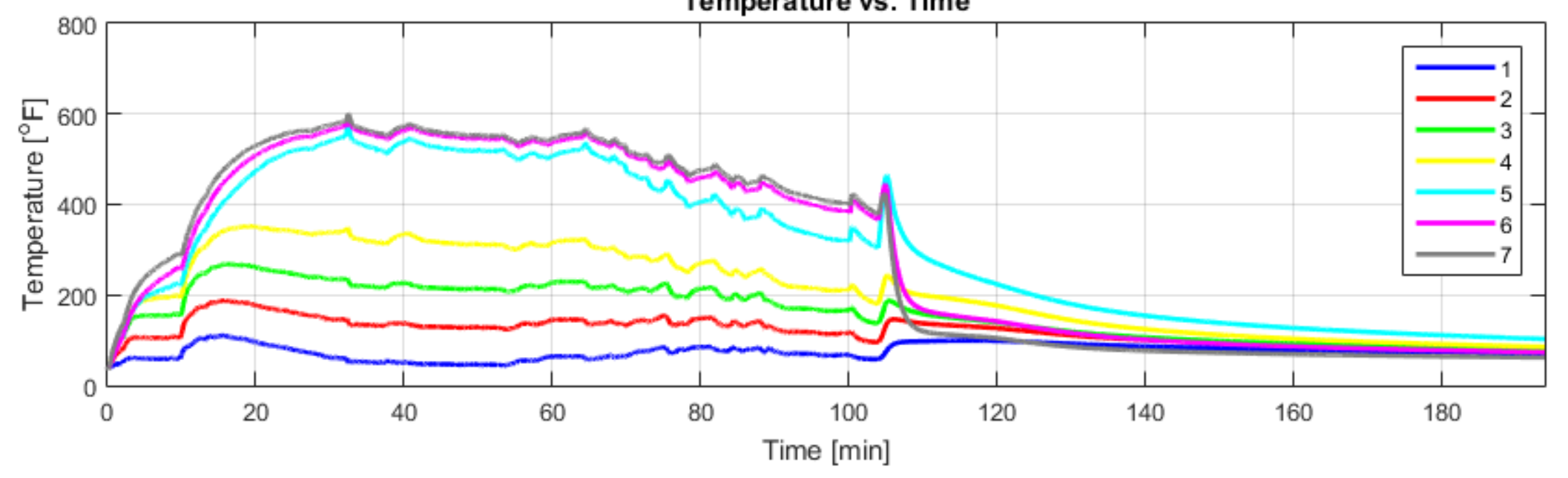




\section{Application: Results}

Front Inner Duct Wall \& Case Walls: Select Locations
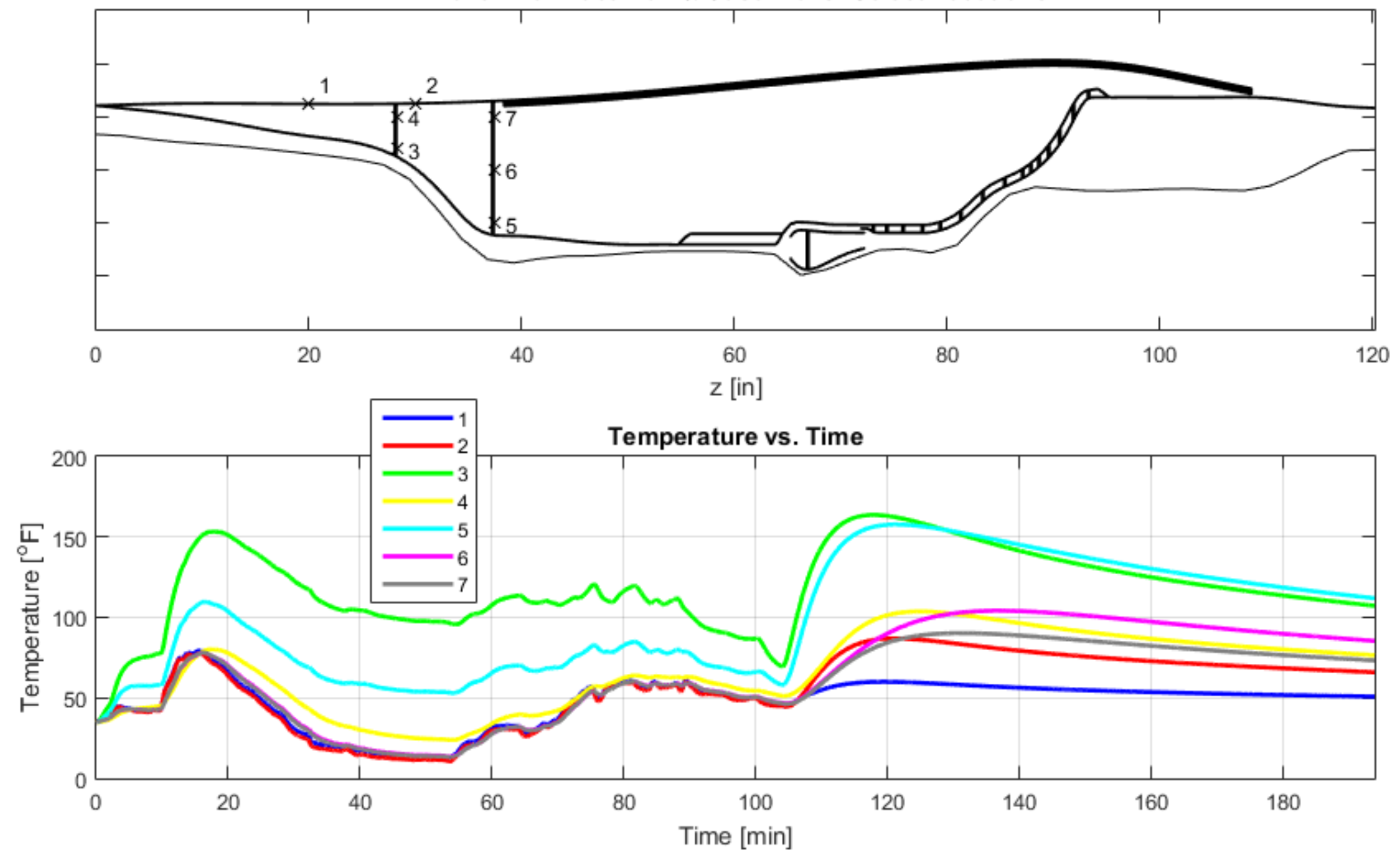


\section{Extra Slides: ANSYS Verification Example}
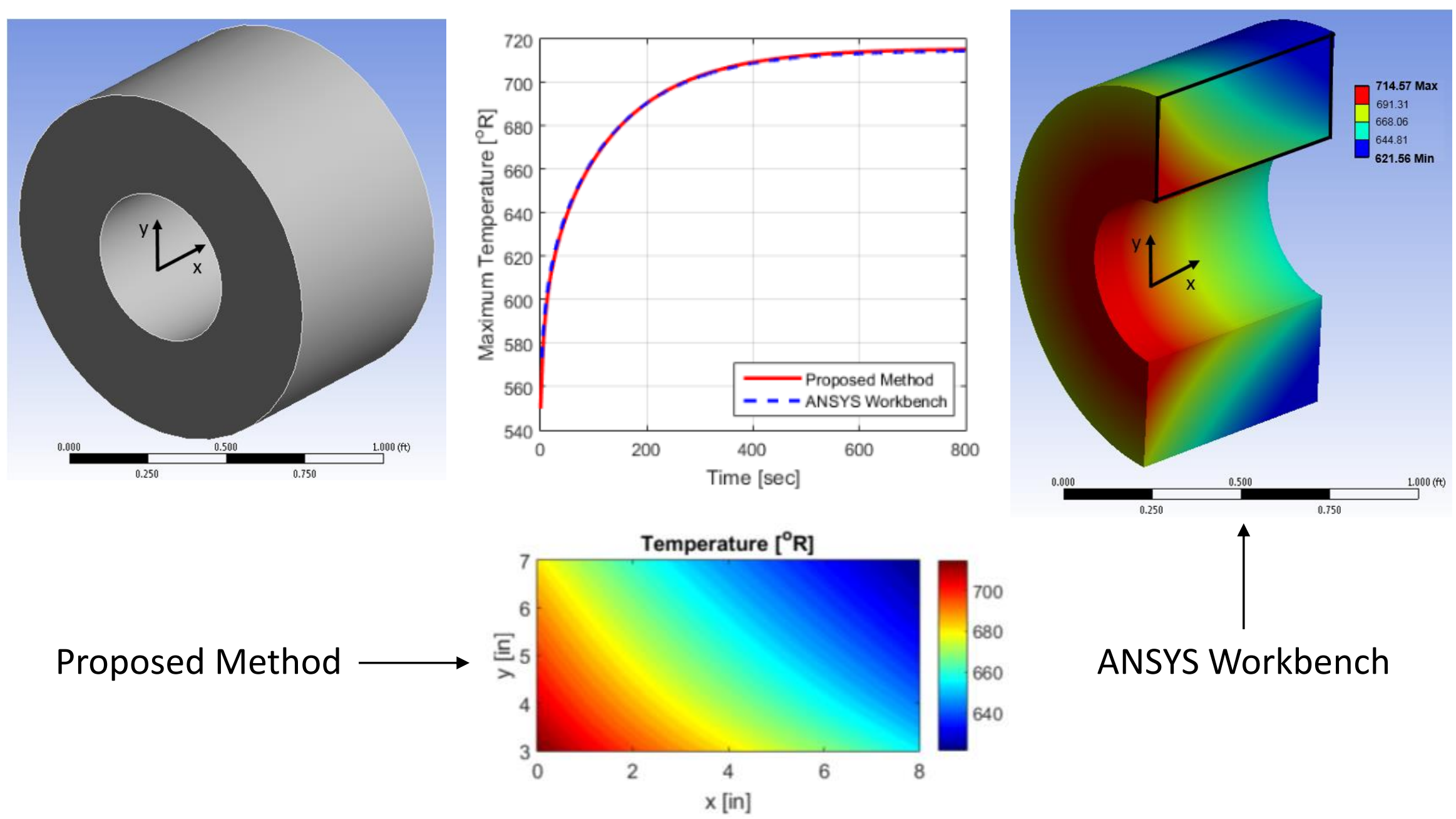

ANSYS Workbench 